\title{
Parâmetros fermentativos, produção de proteína microbiana, concentrações de ureia no leite e no plasma e balanço de nitrogênio de vacas alimentadas com silagem de milho ou cana-de-açúcar com caroço de algodão ${ }^{1}$
}

\section{Daniel de Paula Sousa ${ }^{2 *}$, José Maurício de Souza Campos ${ }^{3}$, Sebastião de Campos Valadares Filho $^{3}$, Rilene Ferreira Diniz Valadares ${ }^{4}$, Camilla Atsumi Zanuncio Sediyama ${ }^{5}$, Júlio César Cardoso $\mathrm{Cruz}^{5}$}

\footnotetext{
1 Pesquisa financiada pela Fundação de Amparo à Pesquisa do Estado de Minas Gerais.

2 Programa de Pós-Graduação em Zootecnia - Universidade Federal de Viçosa.

${ }^{3}$ Departamento de Zootecnia - Universidade Federal de Viçosa.

${ }^{4}$ Departamento de Medicina Veterinária - Universidade Federal de Viçosa.

${ }^{5}$ Curso de Agronomia - Universidade Federal de Viçosa.
}

RESUMO - Doze vacas da raça Holandesa foram distribuídas em três quadrados latinos $4 \times 4$ com o objetivo de avaliar o pH, o N-amoniacal, a produção de proteína microbiana, o número de protozoários no rúmen, a concentração de N-ureia no plasma e no leite e balanço de nitrogênio. Os tratamentos consistiram de silagem de milho ou cana-de-açúcar contendo 0, 7 ou 14\% de caroço de algodão. Não houve diferença no pH quando fornecida cana-de-açúcar, apesar da diminuição dos valores após o início da alimentação. Os valores de $\mathrm{N}$-amoniacal mantiveram-se acima de $15 \mathrm{mg} / \mathrm{dL}$, após 6 horas de alimentação, apenas quando fornecida silagem de milho e cana-de-açúcar com 7\% de caroço de algodão. O maior consumo de MS e nutrientes obtido com a silagem de milho implicou em menor eficiência de uso do nitrogênio e maiores excreções de N-ureia na urina em relação às demais dietas (150,6 vs 96,0 mg/kg PV). O fornecimento de cana-de-açúcar com 7\% de caroço de algodão promoveu maiores quantidades de purinas totais (PT), purinas absorvidas (PA), nitrogênio microbiano (207, 6 vs 185,2 g/dia) e melhor balanço de compostos nitrogenados (31,5 vs 15,5) em relação às demais dietas com canade-açúcar. O menor consumo de MS e extrato etéreo quando fornecida cana-de-açúcar sem caroço de algodão resultou em maior número de protozoários (129,4 vs 34,0 × 103/mL), maior excreção urinária de nitrogênio e menor síntese de proteína microbiana em relação às demais dietas, o que indica falta de sincronização na degradação da energia e proteína na relação volumoso:concentrado proposta neste experimento.

Palavras-chave: ácido úrico, alantoína, creatinina, nitrogênio amonical, protozoários

\section{Fermentative parameters, microbial protein production, plasma and milk urea concentration and nitrogen balance of milking cows fed maize silage or sugarcane with whole cottonseed}

\footnotetext{
ABSTRACT - Twelve cows were allotted to three $4 \times 4$ Latin Squares to evaluate $\mathrm{pH}$, ammonium nitrogen, microbial protein production, number of protozoa in the rumen, plasma and milk urea concentration and balance of nitrogen compounds. Treatments consisted of maize silage or sugarcane with whole cottonseed, at 0,7 or $14 \%$. There were no differences on $\mathrm{pH}$ between sugarcane treatments, despite the reduction of values after the beginning of feeding. Ammonium nitrogen values were kept above $15 \mathrm{mg} / \mathrm{dL}$ after 6 hours of the beginning of feeding by maize silage and sugarcane with $7 \%$ whole cottonseed treatment. The higher DM and nutrients intake by maize silage treatment implied in less efficient use of nitrogen with higher urine N-urea excretion compared to other treatments (150.6 vs $96.0 \mathrm{mg} / \mathrm{kg}$ BW). Sugarcane with 7\% whole cottonseed treatment obtained greater amounts of total purines (PT), absorbed purines (PA), microbial nitrogen (207,6 vs 185,2 g/d) and better balance of nitrogen compounds (31,5 vs 15,5) in relation to other sugarcane treatments. The lower DM and EE intake when supplied sugarcane without whole cottonseed resulted on high protozoa counts (129.4 vs $34.0 \times 10^{3} / \mathrm{mL}$ ), higher urine nitrogen excretion and lower microbial protein synthesis compared to other treatments, which indicates lack of energy and protein degradation synchronism, on forage:concentrate ratio proposed by this experiment.
}

Key Words: allantoin, ammonium nitrogen, creatinine, protozoan, uric acid

Este artigo foi recebido em 1/4/2008 e aprovado em 5/11/2008.

Correspondências devem ser enviadas para: psousadaniel@hotmail.com

*Endereço atual: Universidade Federal do Mato Grosso 


\section{Introdução}

Na tentativa de aumentar a produtividade, busca-se conhecer todos os fatores que influenciam o consumo animal e quais, em cada caso, limitam a resposta animal (Paulino et al., 2001). Um dos pontos fundamentais é o funcionamento ruminal, pois é desejável a manutenção de um padrão de fermentação uniforme, com pH e nitrogênio amoniacal adequados e disponibilidade de substratos energéticos para maior síntese de proteína microbiana (Paulino et al., 2001).

A faixa de $\mathrm{pH}$, para que haja atividade normal no rúmen, segundo Van Soest (1994), é de 6,7 \pm 0,5 e deve ser mantida constante, principalmente por meio do tamponamento do rúmen pela saliva e pela remoção dos ácidos graxos voláteis por absorção (Faria \& Huber, 1984). O nível de nitrogênio amoniacal mínimo para que haja crescimento microbiano é de $5 \mathrm{mg} / \mathrm{dL}$, segundo Satter \& Slyter (1974). No entanto, para obtenção de crescimento microbiano máximo foi estimado faixa de 15,0 a 20,0 mg/dL (Leng \& Nolan, 1984).

A concentração de amônia no líquido ruminal depende das taxas relativas de entrada e remoção (Nolan, 1993) e indica a eficiência nos processos de síntese microbiana e de sincronização entre as taxas de digestão de carboidratos e proteínas (Poppi \& Mclennan, 1995). Quando a velocidade de produção de amônia pelos microrganismos não é acompanhada pela velocidade de utilização, a partir da digestão dos carboidratos, aumentam a excreção de compostos nitrogenados e a perda de proteína da dieta (Morrison \& Mackie, 1996).

A principal forma de eliminação do nitrogênio da dieta é a ureia, que é formada a partir da amônia absorvida no rúmen (Van der Walt, 1993). O aumento nos níveis de amônia no líquido ruminal, decorrentes do aumento do teor protéico da dieta e/ou da má utilização da proteína dietética, estão relacionados a aumentos nos níveis de ureia no plasma e no leite (no caso de vacas leiteiras). Segundo Broderick (1995), citado por Valadares (1997), tentativas têm sido feitas para utilizar as concentrações de ureia no leite e plasma como indicadores da eficiência de utilização da proteína bruta da dieta e, junto as demais variáveis auxiliar no entendimento e busca pela melhora na eficiência nutricional do animal.

Objetivou-se avaliar o pH, o N-amoniacal, a produção de proteína microbiana e protozoários no rúmen, a concentração de ureia no leite e no plasma e o balanço de compostos nitrogenados de vacas lactantes alimentadas com silagem de milho ou cana-de-açúcar parcialmente substituída pelo caroço de algodão.

\section{Material e Métodos}

O experimento foi conduzido na Unidade de Ensino, Pesquisa e Extensão em Gado de Leite (UEPE-GL) do Departamento de Zootecnia (DZO), na Universidade Federal de Viçosa (UFV), em Viçosa, Minas Gerais, no período de agosto a outubro de 2001. Foram utilizadas 12 vacas multíparas lactantes, 7/8 Holandês Gir, com aproximadamente 70 dias em lactação, distribuídas em três quadrados latinos $4 \times 4$. Os critérios para alocação dos animais em cada quadrado latino foram a produção de leite atual, a produção na lactação anterior, o peso, o estágio de lactação e o número de parições.

O experimento foi constituído de quatro períodos de 21 dias: os 14 primeiros de adaptação às dietas e os 7 dias posteriores, de coleta. Os animais utilizados no experimento foram manejados em baias individuais, tipo tie stall, onde foram alimentados e ordenhados duas vezes ao dia, com controle diário da oferta e das sobras de alimentos. As dietas foram formuladas segundo recomendações do NRC (2001) para atender às necessidades de vacas produzindo $25 \mathrm{~kg} /$ dia de leite e continham 37 a $40 \%$ de FDN e $15 \%$ de PB (Tabela 1 ).

Em uma das dietas, utilizou-se silagem de milho (Zea mays) como volumoso, enquanto, nas demais, o volumoso oferecido foi cana-de-açúcar (Saccharum officinarum, L) substituída por caroço de algodão nos níveis de 0,7 ou $14 \%$ da matéria seca total, representando os consumos médios diários de 0; 1,50 e 3,00 kg de caroço de algodão, respectivamente (Tabela 1). A relação volumoso:concentrado em todas as dietas foi 60:40 com base na matéria seca, considerando o caroço de algodão como volumoso. Nas dietas à base de cana-de-açúcar, corrigiu-se o teor proteico por meio da adição de $1 \%$ da mistura ureia+sulfato de amônio (SA), na proporção 9:1, com base na matéria natural.

Nas amostras dos alimentos fornecidos, das sobras e das fezes, foram determinados os teores de MS, MO, cinzas, nitrogênio total (Kjehldal) e extrato etéreo (em aparelho Soxhlet), de acordo com metodologia descrita por Silva \& Queiroz (2002). Os teores de FDN, FDA e lignina foram estimados pelos métodos sugeridos por Van Soest et al. (1991), utilizando-se a amilase sem adição de sulfito de sódio na determinação da FDN.

Os teores de carboidratos totais (CT) dos alimentos foram calculados conforme descrito por Sniffen et al. (1992): $\mathrm{CT}=100-(\% \mathrm{~PB}+\% \mathrm{EE}+\%$ Cinzas $)$. A composição em carboidratos não-fibrosos (CNF) foi estimada subtraindo-se da porcentagem total de carboidratos os teores de fibra em 
detergente neutro (FDN): $\mathrm{CNF}=\mathrm{CT}-\mathrm{FDN}$; e os teores de nutrientes digestíveis totais (NDT) foram calculados segundo o NRC (2001): NDT (\%) = PBD + FDND+ CNFD+2,25EED, em que: $\mathrm{PBD}$ = proteína bruta digestível; FDND = fibra em detergente neutro digestível; CNFD = carboidratos não-fibrosos digestíveis; e EED = extrato etéreo digestível.

As amostras compostas de leite foram obtidas no $18^{\circ}$ dia de cada período experimental para análises de compostos nitrogenados totais, alantoína e ureia. As amostras de leite foram primeiramente desproteinizadas. Uma amostra de $10 \mathrm{~mL}$ de leite foi misturada com $5 \mathrm{~mL}$ de ácido tricloroacético a $25 \%$ e deixada em repouso por 10 minutos. Posteriormente, o conteúdo foi filtrado em papel-filtro e o filtrado armazenado a $-20^{\circ} \mathrm{C}$.

Análises de creatinina e ureia no plasma foram realizadas a partir de coleta de sangue realizada no $19^{\circ}$ dia de cada período experimental. Amostras spot de urina foram obtidas no 20 으 dia de cada período experimental, aproximadamente 4 horas após a alimentação, durante micção espontânea. As alíquotas de $40 \mathrm{~mL}$ foram diluídas em ácido sulfúrico a 0,036N; e o pH da solução foi ajustado a valores inferiores a 3 para evitar destruição bacteriana dos derivados de purinas e precipitação de ácido úrico. As amostras foram armazenadas a $-20^{\circ} \mathrm{C}$ para posteriores análises de creatinina, ureia e derivados de purina (alantoína e ácido úrico). A ureia foi determinada na urina, no plasma e no leite desproteinizado e a creatinina na urina, usando-se kits comercias (Labtest). As análises de derivados de purina (alantoína e ácido úrico) foram feitas pelo método colorimétrico, segundo Fujihara et al. (1987), descrito por Chen \& Gomes (1992).

O líquido ruminal foi coletado via fístula ruminal, no 21 을a, para determinação do $\mathrm{pH}$, da concentração de amônia e da concentração de protozoários. A concentração de amônia foi determinada nos tempos imediatamente antes da alimentação (zero), 2, 4 e 6 horas após o início da alimentação e a concentração de protozoários, nos tempos zero e 6 horas após a alimentação. Duas alíquotas de $40 \mathrm{~mL}$ do filtrado do líquido ruminal em gaze foram obtidas por cada animal e tempo de coleta. Em uma delas, determinou-se, imediatamente, o pH por meio de potenciômetro digital, adicionou-se $1 \mathrm{~mL}$ de ácido sulfúrico 50\% e armazenou-se a amostra em congelador a $-5^{\circ} \mathrm{C}$ para posterior determinação do $\mathrm{N}-\mathrm{NH}_{3}$ ruminal. A segunda alíquota foi adicionada de $40 \mathrm{~mL}$ de formaldeído comercial $(37,4 \%)$ e armazenada a $5^{\circ} \mathrm{C}$ para posterior contagem de protozoários no líquido ruminal (Dehority, 1984). Os protozoários foram contados

Tabela 1 - Proporção e composição bromatológica dos ingredientes das dietas

\begin{tabular}{|c|c|c|c|c|}
\hline \multirow[b]{2}{*}{ Item } & \multirow[b]{2}{*}{ Silagem de milho } & \multicolumn{3}{|c|}{ Cana-de-açúcar } \\
\hline & & $\begin{array}{l}\text { Sem caroço } \\
\text { de algodão }\end{array}$ & $\begin{array}{c}\text { Com } 7 \% \text { de } \\
\text { caroço de algodão }\end{array}$ & $\begin{array}{c}\text { Com } 14 \% \text { de } \\
\text { caroço de algodão }\end{array}$ \\
\hline Silagem de milho & 60,00 & - & - & - \\
\hline Cana-de-açúcar & - & 60,00 & 53,00 & 46,00 \\
\hline Caroço de algodão & - & - & 7,00 & 14,00 \\
\hline Farelo de algodão & 3,00 & 3,00 & 3,00 & 3,00 \\
\hline Ureia+sulfato de amônia & 0,60 & 0,6 & 0,53 & 0,46 \\
\hline Suplemento mineral & 1,30 & 1,75 & 1,75 & 1,74 \\
\hline \multicolumn{5}{|l|}{ Composição química } \\
\hline Matéria seca (\%) & 53,57 & 52,17 & 55,84 & 59,45 \\
\hline NIDA $^{1}$ & 5,28 & 3,93 & 3,89 & 3,87 \\
\hline Extrato etéreo (\% MS) & 2,10 & 1,34 & 2,35 & 3,76 \\
\hline Carboidratos totais (\% MS) & 76,69 & 79,60 & 78,35 & 77,70 \\
\hline Carboidratos não-fibrosos (\% MS) & 36,65 & 41,59 & 41,04 & 40,69 \\
\hline Fibra em detergente neutro (\% MS) & 40,04 & 38,01 & 37,31 & 37,01 \\
\hline $\mathrm{FDN}_{\mathrm{CP}}(\% \mathrm{MS})$ & 38,34 & 36,55 & 35,94 & 35,30 \\
\hline Fibra em detergente ácido (\% MS) & 20,83 & 23,10 & 22,65 & 22,65 \\
\hline Lignina (\% MS) & 4,21 & 5,17 & 5,08 & 5,02 \\
\hline Nutrientes digestíveis totais (\% MS) & 65,94 & 66,85 & 67,72 & 71,79 \\
\hline
\end{tabular}

$1 \%$ do nitrogênio total; NIDN = nitrogênio insolúvel em detergente neutro; NIDA = nitrogênio insolúvel em detergente ácido; FDNcp = FDN corrigida para cinzas e proteína. 
em câmara de contagem de Sedgwick-Rafter com capacidade para $1 \mathrm{~mL}$ e microscópio ótico comum provido de retículo com área de $0,4362 \mathrm{~mm}^{2}$.

A determinação do $\mathrm{N}-\mathrm{NH}_{3}$ ruminal foi realizada após a centrifugação das amostras a 3.000 rpm por 15 minutos, utilizando-se o sobrenadante, segundo o método microKjeldahl (Silva \& Queiroz, 2002). O balanço dos compostos nitrogenados ( $\mathrm{N}$ ) foi obtido pela diferença entre o total de $\mathrm{N}$ ingerido e o total de $\mathrm{N}$ excretado nas fezes, no leite e na urina. A determinação do $\mathrm{N}$ total no leite e na urina foi feita segundo Silva \& Queiroz (2002).

A excreção total de derivados de purina foi calculada pela soma das quantidades de alantoína e ácido úrico excretados na urina e da quantidade de alantoína excretada no leite, expressas em mmol/dia. O volume urinário total diário foi estimado a partir da proposição de excreção de 29,00 mg/kg do peso vivo (PV) de creatinina (Valadares et al., 1999) e da concentração de creatinina na amostra de urina, segundo Rennó et al. (2000).

As purinas absorvidas (X, mmol/dia) foram calculadas a partir da excreção de derivados de purina (Y, mmol/dia), por meio da equação $\mathrm{Y}=0,84 \mathrm{X}+0,236 \mathrm{PV}^{0,75}$, em que 0,84 é a recuperação de purinas absorvidas como derivados de purinas e $0,236 \mathrm{PV}^{0,75}$, a contribuição endógena para excreção de purinas, valor proposto por Orellana Boero (2001).

A síntese de compostos nitrogenados microbianos no rúmen ( $\mathrm{Y}, \mathrm{g} \mathrm{N} / \mathrm{dia})$ foi calculada em relação às purinas absorvidas (X, mmol/dia), por meio da equação:

$\mathrm{Y}=(70 \mathrm{X}) /(0,83 \times 0,116 \times 1000)$, em que 70 representa o conteúdo de $\mathrm{N}$ nas purinas ( $\mathrm{mg} \mathrm{N} / \mathrm{mmol}$ ); 0,83, a digestibilidade das purinas microbianas; e 0,116 , a relação N-purina:N total nas bactérias (Chen \& Gomes, 1992).

No caso dos dados de $\mathrm{pH}$, amônia e protozoários ruminais, as avaliações realizadas em diversos horários foram consideradas diferentes observações da função multivariada (SAS, 1991); os dados foram submetidos à análise de variância multivariada, segundo Schabenberger \& Pierce (2002), e a comparação das diferenças mínimas significativas das médias a 5\% de significância, utilizando-se o programa SAS, versão 8.0, do Instituto SAS.

Os dados dos níveis plasmáticos de ureia, excreções de ureia e alantoína no leite e de ureia, alantoína e ácido úrico na urina, bem como a síntese de proteína microbiana e o balanço de compostos nitrogenados, foram submetidos à análise de variância, segundo o seguinte modelo matemático (SAS, 1991):

Yijkl $=\mu+\operatorname{Vi}(l)+P j(l)+T k+Q l+T Q k l+\varepsilon i j l$,

em que Yijkl = observação na vaca $i$, no período $j$, submetida ao tratamento $\mathrm{k}$, no quadrado latino $\mathrm{l} ; \mu=$ efeito geral da média; $\mathrm{Vi}(\mathrm{l})$ = efeito da vaca $\mathrm{i}$, dentro do quadrado latino $\mathrm{l}$, de modo que $\mathrm{i}=1,2,3,4 ; \mathrm{Pj}(\mathrm{l})=$ efeito do período $\mathrm{j}$, dentro do quadrado latino $\mathrm{l}$, em que $\mathrm{j}=1,2,3,4$; $\mathrm{Tk}=$ efeito do tratamento $\mathrm{k}$, em que $\mathrm{k}=1,2,3,4 ; \mathrm{Ql}=$ efeito do quadrado latino l, em que l = 1,2,3; TQkl = efeito da interação entre o tratamento k e o quadrado latino l; e $\varepsilon i j k l=$ erro aleatório associado a cada observação ijkl, eijkl $\sim \operatorname{NID}\left(0, \sigma^{2}\right)$. As médias foram comparadas pelo teste Tukey, a 5\% de probabilidade.

\section{Resultados e Discussão}

Os valores de pH ruminal não sofreram influência direta dos níveis de substituição da cana-de-açúcar por caroço de algodão (Figura 1; Tabela 2); do mesmo modo, não foi observada interação entre nível de caroço de algodão na dieta e o tempo em que foram feitas as coletas. Entretanto, os valores diminuíram com o avanço nos tempos de alimentação; os valores mínimos foram estimados nos tempos de 4 horas após o início da alimentação para a canade-açúcar e após 6 horas para a silagem de milho $(\mathrm{P}<0,05)$. Nenhum dos valores, mesmo os extremos, foram inferiores a 6,0, no qual, segundo Hoover (1986), iniciariam os efeitos deletérios sobre a microbiota celulolítica ruminal.

Os dados corroboram os encontrados por Magalhães et al. (2006) e Valvasori et al. (1998), que substituíram silagem de milho por cana-de-açúcar na dieta de vacas leiteiras e não notaram diferenças no pH entre os tempos de coleta. Esses autores relataram que os menores valores, de 6,63 e 6,3, respectivamente, foram obtidos aproximadamente 4 horas após o início da alimentação. A uniformidade do $\mathrm{pH}$ ruminal entre as dietas pode em parte ser explicada pela forma de fornecimento. Raun et al. (1962) e Faria\& Huber (1984) demonstraram que o uso de rações completas possibilita um padrão mais constante de fermentação no rúmen.

Apesar do aumento do consumo de MS e de carboidratos não-fibrosos na dieta com 7\% de caroço de algodão, em comparação à cana-de-açúcar sem caroço de algodão (17,1 e 7,40 vs 15,5 e 6,74 kg/dia, respectivamente, não foram obtidos menores valores de $\mathrm{pH}$. Esse resultado se deve, em parte, ao fato de o caroço de algodão não ter sido processado - foi fornecido sem a retirada do línter - e ao aumento no consumo de extrato etéreo ( 0,41 vs $0,24 \mathrm{~kg} / \mathrm{dia}$, respectivamente). Segundo dados de Kowalczyk et al. (1977), a adição de gordura influencia positivamente o $\mathrm{pH}$ ruminal e, neste enfoque, especula-se que dietas com sementes oleaginosas têm efeito tamponante.

A concentração amoniacal ruminal foi afetada tanto pelo nível de caroço de algodão na dieta $(\mathrm{P}<0,05)$ como pelo tempo de coleta $(P<0,05)$, mas não houve interação entre 
esses fatores (Figura 2; Tabela 2). O comportamento quadrático está de acordo com o descrito por DelCurto et al. (1990) e, em decorrência da alta proporção de proteína degradada e solúvel no rúmen da silagem de milho e do alto teor de ureia nas dietas com cana-de-açúcar, os teores de amônia foram mais elevados nas primeiras duas horas de alimentação (Hungate, 1966).

Tanto a dieta à base de silagem de milho como a canade-açúcar com 7\% de caroço de algodão mantiveram níveis elevados de amônia ruminal após 6 horas do início da alimentação. Os valores entre 15 e $20 \mathrm{mg} / \mathrm{dL}$ estão dentro do recomendado por Leng \& Nolan (1984) para máximo crescimento microbiano. A manutenção de níveis elevados de amônia é, em parte, explicada pelos maiores consumos de proteína verdadeira e pela menor taxa de degradação do caroço de algodão. Os valores médios de consumo de proteína bruta foram de 3,26; 2,48; 2,67 e 2,45 kg/dia (Sousa et al., 2009) para as dietas à base de silagem de milho e cana-de-açúcar com 0, 7 e 14\% de caroço de algodão, respectivamente.

Quando fornecida a dieta com $14 \%$ de caroço de algodão, foram observadas quantidades consideráveis de sobras de caroço de algodão no cocho, o que reduziu os consumos e aumentou a proporção da proteína vinda da ureia, uma vez que as dietas foram isoproteicas. O baixo consumo de proteína verdadeira pode ter sido responsável pela redução acentuada na concentração até valores inferiores a $5 \mathrm{mg} / \mathrm{dL}$ após 6 horas de alimentação.

Tanto os níveis de caroço de algodão quanto os horários de coleta interferiram $(\mathrm{P}<0,05)$ no número total de protozoários no líquido ruminal (Tabela 3). Os resultados obtidos com o fornecimento de cana-de-açúcar sem caroço de algodão e de silagem de milho estão de acordo com os descritos por Valvassori (1998). Os menores consumos de MS, associados a menores taxas de passagem da cana-deaçúcar, podem ter permitido maiores tempos de retenção e de multiplicação dos protozoários no rúmen. Como o tempo de duplicação da população de protozoários varia de 6 a 48 horas, com média de 24 horas, o menor consumo pode ter influenciado os resultados, ocasionando diferença entre as dietas (Van Soest, 1994).
Do mesmo modo, a concentração de protozoários no líquido ruminal diminuiu quando fornecidas cana-de-açúcar com caroço de algodão. Além de propiciar maiores consumos de matéria seca, os maiores teores de extrato etéreo do caroço de algodão podem diminuir a concentração de protozoários no líquido ruminal, conforme revisão apresentada por Jenkins (1993). Mohamed et al. (1988) verificaram menores relações acetato:propionato (A:P) e redução na população de protozoários como resultado da inclusão de caroço de algodão (16,5\% da MS) ou óleo de caroço de algodão (4\% da MS) na dieta de vacas em lactação. Esses autores relataram ainda que as alterações no número de protozoários foram consistentes com a redução na relação acetato:propionato e na digestibilidade da matéria seca da dieta.

A excreção média de ácido úrico das dietas experimentais, de 23,59 mmol/dia, foi semelhante à observada por Oliveira et al. (2001), de 29,32 mmol/dia, e superior à descrita por Mendonça et al. (2004), de $15 \mathrm{mmol} /$ dia (Tabela 4). A alantoína excretada na urina representou em média $86,21 \%$ do total de derivados de purinas, valor semelhante aos encontrados por Vagnoni et al. (1997), de 86,6\%; Oliveira et al. (2001), de 87,8\%; Silva et al. (2001), de 86,1\%; Mendonça et al. (2004), de 90,8\%; e Souza et al. (2006), de

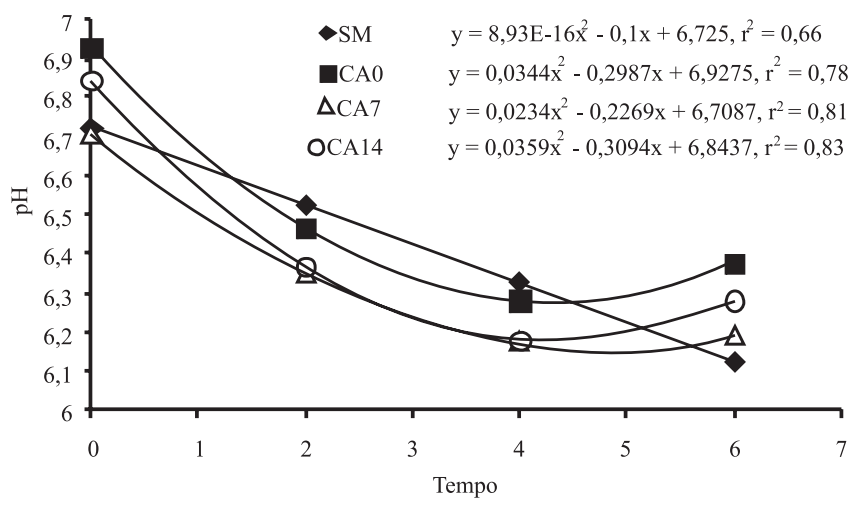

Figura 1 - Estimativas do pH ruminal em diversos tempos após o início da alimentação (horas) em cada nível de substituição da cana-de-açúcar pelo caroço de algodão. $\mathrm{SM}=$ silagem de milho; $\mathrm{CA}$ = cana-de-açúcar substituída por 0,7 e $14 \%$ de caroço de algodão.

Tabela 2 - Concentração média de amônia ruminal (mg/dL) e pH ruminal em vacas leiteiras mantidas com dietas à base de silagem de milho ou cana-de-açúcar com caroço de algodão

\begin{tabular}{lcccc}
\hline & & \multicolumn{2}{c}{ Cana-de-açúcar } \\
\cline { 3 - 5 } Parâmetro & Silagem de milho & Sem caroço de algodão & Com $7 \%$ de caroço de algodão & Com $14 \%$ de caroço de algodão \\
pH & 6,42 & 6,51 & 6,36 & 6,42 \\
Amônia ruminal & $19,7 \mathrm{a}$ & $13,4 \mathrm{c}$ & $16,0 \mathrm{~b}$ & $12,3 \mathrm{c}$ \\
\hline
\end{tabular}

Médias seguidas de mesma letra maiúscula nas colunas e de letra minúscula nas linhas não diferem entre si pelo teste de Tukey a 5\% de probabilidade. 
82,2\% (Tabela 4). A excreção de alantoína no leite em relação à excreção total de derivados de purina foi de 4,57\% e está de acordo com os valores descritos por Valadares et al. (1999), de 4,2 a 5,7\%; Oliveira et al. (2001), de 4,5\%; e Souza et al. (2006), de 5,7\% (Tabela 4). A maior produção de leite nos animais alimentados com silagem de milho e cana-de-açúcar com caroço de algodão (Sousa et al., 2009) explica, em parte, a maior excreção de alantoína no leite, pois, segundo Gonda \& Lindenberg (1997), a produção de leite influencia a concentração e a quantidade de alantoína excretada no leite.

Ovalor médio encontrado de N-microbiano, de 198,87 g/dia (Tabela 4), foi semelhante aos obtidos por Mendonça et al. (2004) e Oliveira et al. (2001), de 193,2 e 193,4, em vacas de produções médias de 18,9 e 22,0 kg leite/dia, respectivamente. Todavia, foram inferiores aos encontrados por Valadares et al. (1999), que registraram valores de 278 a 419 g/dia em animais com maiores produções diárias de leite.

Ressalta-se que as quantidades de N-microbiano produzidas representaram 38,4; 45,1; 46,9 e 52,9\% do N ingerido para as dietas à base de silagem de milho e cana-de-açúcar com caroço de algodão, respectivamente, e que a eficiência de síntese microbiana média foi de 10,4 g/100 g de NDT, que está abaixo do valor preconizado pelo NRC (2001), de 13,0 g /100 g NDT.

A cana-de-açúcar sem caroço de algodão foi inferior à silagem de milho para a maioria dos parâmetros

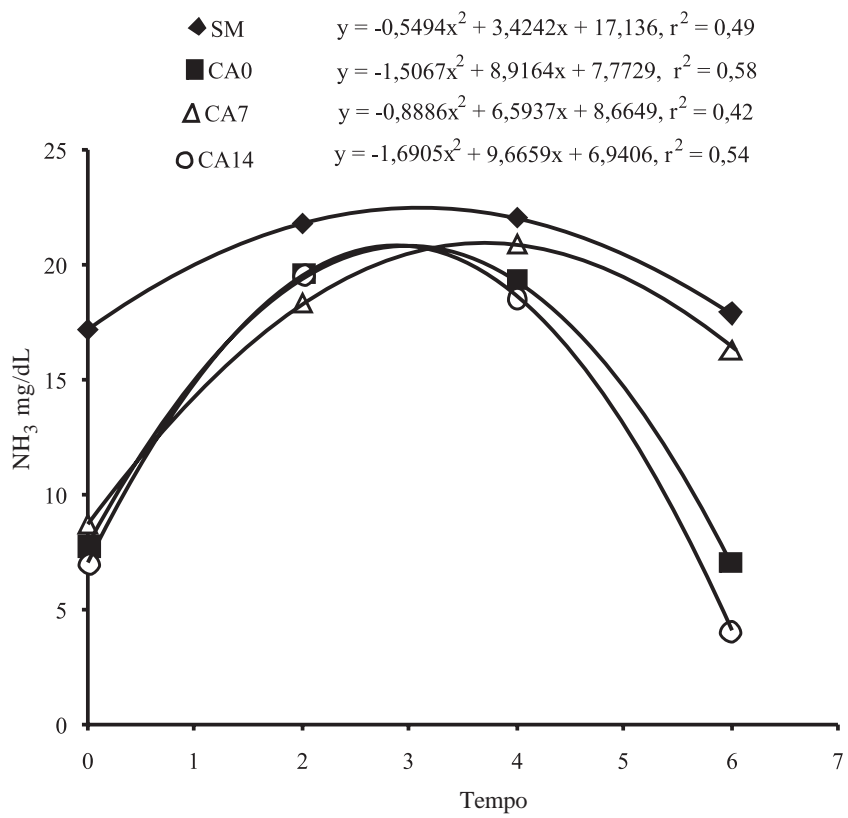

Figura 2 - Concentração de amônia ruminal após o início da alimentação (SM = silagem de milho; $\mathrm{CA}$ = cana-deaçúcar substituída por 0,7 ou $14 \%$ de caroço de algodão). relacionados tanto à determinação quanto aos valores de $\mathrm{N}$-microbiano. Mendonça et al. (2004) também observaram diferenças na síntese de proteína microbiana entre as dietas à base de silagem de milho e cana-de-açúcar na relação volumoso:concentrado (V:C) de 60:40. Entretanto, a cana-de-açúcar com menor V:C (50:50) promoveu maiores excreções de purina, que foram semelhantes às obtidas com o fornecimento de silagem de milho. Esses resultados indicam que dietas com cana-de-açúcar em altas relações volumoso:concentrado parecem ser ineficientes quanto à quantidade e sincronização na disponibilidade proteína: energia e no favorecimento do ambiente ruminal, o que afeta o crescimento microbiano (Clark et al., 1992; Jenkins, 1993).

A adição de caroço de algodão nas dietas com canade-açúcar aumentou as excreções de purina e a síntese de proteína microbiana, do mesmo modo como observado por Nevel \& Demeyer (1988). Foram observados maiores consumos de MS (Sousa et al., 2008), que resultaram em maiores quantidades de nutrientes disponíveis no rúmen para crescimento microbiano. Além disso, o decréscimo no número de protozoários pode ter influenciado, o que fez com que os valores de proteína microbiana obtidos com a cana-de-açúcar com 7\% de caroço de algodão fossem semelhantes aos determinados com silagem de milho.

As dietas não influenciaram as concentrações de N-ureia no plasma e no leite, no entanto, a excreção urinária de $\mathrm{N}$-ureia observada quando fornecida silagem de milho foi maior $(\mathrm{P}<0,05)$ que a obtida com o fornecimento das dietas à base de cana-de-açúcar (Tabela 5). Esses resultados diferem dos relatados por Mendonça et al. (2004), que encontraram maiores concentrações de $\mathrm{N}$-ureia no plasma e no leite para a dieta com cana-de-açúcar (relação volumoso:concentrado 60:40) em relação à silagem de milho, assim como excreções semelhantes de $\mathrm{N}$-ureia na urina entre as dietas.

Os teores de proteína não-verdadeira foram 5,61; 8,01; 7,68 e 7,14\% da MS para as dietas à base de silagem de milho e de cana-de-açúcar com caroço de algodão, respectivamente. No entanto, o aumento no teor de nitrogênio não-proteico nas dietas de cana-de-açúcar não aumentou as concentrações de $\mathrm{N}$-ureia no plasma nem as excreções de $\mathrm{N}$-ureia na urina, assim como verificado por Oliveira et al. (2001) e Mendonça et al. (2004). A maior excreção de $\mathrm{N}$-ureia na urina quando fornecida silagem de milho possivelmente se deve às maiores ingestões de nitrogênio, o que levou a menores eficiências pelos animais. Segundo Valadares et al. (1997), baixas ingestões de compostos nitrogenados possibilitam maior conservação 
Tabela 3 - Concentração média de protozoários (x1000/mL) no líquido ruminal em vacas leiteiras mantidas com dietas à base de silagem de milho ou cana-de-açúcar com caroço de algodão

\begin{tabular}{lcccr}
\hline \multirow{2}{*}{ Tempo } & Silagem de & \multicolumn{3}{c}{ Cana-de-açúcar } \\
\cline { 3 - 5 } & milho & $\begin{array}{c}\text { Sem caroço } \\
\text { de algodão }\end{array}$ & $\begin{array}{c}\text { Com } 7 \% \text { de } \\
\text { caroço de algodão }\end{array}$ & $\begin{array}{c}\text { Com } 14 \% \text { de } \\
\text { caroço de algodão }\end{array}$ \\
\hline Antes da alimentação & $51,6 \mathrm{bA}$ & $131,1 \mathrm{aA}$ & $42,0 \mathrm{bA}$ & $S_{\bar{X}}$ \\
6 horas após alimentação & $25,5 \mathrm{bB}$ & $127,6 \mathrm{aA}$ & $39,2 \mathrm{bA}$ & 0,10 \\
\hline
\end{tabular}

$S_{x}=$ erro-padrão da média.

Médias seguidas de mesma letra maiúscula nas colunas e minúscula nas linhas não diferem entre si pelo teste de Tukey a 5 \%.

Tabela 4 - Médias diárias das excreções de derivados de purina e compostos nitrogenados microbianos em vacas leiteiras mantidas com dietas à base de silagem de milho ou cana-de-açúcar com caroço de algodão

\begin{tabular}{|c|c|c|c|c|c|}
\hline \multirow[b]{2}{*}{ Item } & \multirow[b]{2}{*}{$\begin{array}{l}\text { Silagem de } \\
\text { milho }\end{array}$} & \multicolumn{3}{|c|}{ Cana-de-açúcar } & \multirow[b]{2}{*}{$S_{\bar{X}}$} \\
\hline & & $\begin{array}{l}\text { Sem caroço } \\
\text { de algodão }\end{array}$ & $\begin{array}{c}\text { Com } 7 \% \text { de } \\
\text { caroço de algodão }\end{array}$ & $\begin{array}{c}\text { Com } 14 \% \text { de } \\
\text { caroço de algodão }\end{array}$ & \\
\hline Alantoína no leite (mmol/dia) & $13,6 a$ & $10,7 b$ & $11,3 a b$ & $11,6 a b$ & 0,02 \\
\hline Ácido úrico na urina (mmol/dia) & $29,2 \mathrm{a}$ & $19,5 c$ & $22,1 \mathrm{bc}$ & $23,6 b$ & 0,04 \\
\hline Purinas totais (mmol/dia) & $278,9 a$ & $226,5 c$ & 266,3ab & $256,4 b$ & 0,48 \\
\hline Proteína bruta mic/100gNDT) & 10,0 & 10,3 & 10,9 & 10,5 & 0,02 \\
\hline
\end{tabular}

$S_{X}=$ erro-padrão da media.

Médias, nas linhas, seguidas de uma mesma letra não diferem estatisticamente pelo teste de Tukey a $5 \%$ de probabilidade.

Tabela 5 - Concentrações médias de N-ureia no plasma e no leite, excreções médias diárias de N-ureia, consumos de nitrogênio, excreções médias diárias de $\mathrm{N}$ nas fezes e na urina e balanço de compostos nitrogenados nas dietas experimentais

\begin{tabular}{|c|c|c|c|c|c|}
\hline Item & $\begin{array}{l}\text { Silagem de } \\
\text { milho }\end{array}$ & \multicolumn{3}{|c|}{ Cana-de-açúcar } & $S_{\bar{X}}$ \\
\hline Plasma (mg/dL) & 19,5 & 19,0 & 17,4 & 17,1 & 0,03 \\
\hline Leite (mg/dL) & 12,2 & 12,9 & 13,4 & 12,0 & 0,03 \\
\hline Urina $(\mathrm{mg} / \mathrm{kg} \mathrm{PV})$ & $150,6 a$ & $97,5 b$ & $101,6 b$ & $88,9 b$ & 0,30 \\
\hline Leite/Plasma & \multicolumn{5}{|c|}{ Compostos nitrogenados } \\
\hline Ingestão (g/dia) & $540,8 a$ & $397,5 c$ & $426,7 b$ & $391,7 c$ & 0,24 \\
\hline Fezes (g/dia) & $170,0 \mathrm{a}$ & $125,8 c$ & $146,7 \mathrm{~b}$ & 138,3 bc & 0,16 \\
\hline Urina (g/dia) & $200,8 a$ & $163,3 b$ & $150,0 \mathrm{bc}$ & $138,3 c$ & 0,36 \\
\hline Leite (g/dia) & $123,3 a$ & $92,5 b$ & $97,5 b$ & $101,7 b$ & 0,10 \\
\hline Balanço N & $46,4 \mathrm{a}$ & $16,6 \mathrm{c}$ & $31,5 b$ & $14,3 \mathrm{c}$ & 0,08 \\
\hline
\end{tabular}

$S_{x}=$ erro-padrão da media.

Médias, nas linhas, seguidas de mesma letra não diferem estatisticamente pelo teste de Tukey a 5\% de probabilidade.

de ureia, ao passo que maior excreção de ureia ocorre mediante altas ingestões de nitrogênio.

Apesar de os valores médios de NUP estarem acima dos limites propostos, os valores médios de NUL encontram-se abaixo dos limites estabelecidos, o que evidencia que não há perdas da proteína dietética. Valores de NUP entre 14 e $16 \mathrm{mg} / \mathrm{dL}$ (Valadares et al., 1997) e de NUL entre 24 a $25 \mathrm{mg} / \mathrm{dL}$ (Oliveira et al., 2001) corresponderam à máxima eficiência microbiana e representam limites nos quais se iniciariam as perdas de proteína dietética.

A dieta à base de silagem de milho, em virtude do maior consumo de nitrogênio e da maior produção de leite, apresentou as maiores $(\mathrm{P}<0,05)$ excreções de nitrogênio, tanto nas fezes como no leite e na urina.

Apesar de não terem sido observadas diferenças significativas, a concentração de N-ureia no leite em relação 
à do plasma foi maior quando fornecida a cana-de-açúcar com 7\% de caroço de algodão (em torno de 0,11 superior). Os menores teores $\mathrm{N}$-ureia na urina foram observados quando fornecida cana-de-açúcar com 14\% de caroço de algodão e os menores teores de $\mathrm{N}$-ureia no plasma (em torno de $10 \%)$ foram registrados nos dois níveis de caroço de algodão em comparação à cana-de-açúcar sem caroço de algodão. Estes resultados, aliados à maior síntese de proteína microbiana, evidenciam o melhor balanço proteico e melhor sincronização nas taxas de degradação dos carboidratos em relação à proteína nas dietas cana-de-açúcar com caroço de algodão (Poppi \& Mclennan, 1995).

\section{Conclusões}

O caroço de algodão, quando adicionado em níveis adequados, pode aumentar a energia e melhorar as características nutricionais de dietas contendo volumosos como a cana-de-açúcar, com elevados teores de fibra de baixa digestibilidade, sem alterar o $\mathrm{pH}$ a níveis indesejáveis. Entre os níveis de substituição da cana-de-açúcar por caroço de algodão, o de 7\% é mais adequado, pois promove a manutenção de níveis elevados de amônia após 6 horas do início da alimentação, além de produções de proteína microbiana semelhantes à obtida com silagem de milho, com melhor balanço de compostos nitrogenados em relação ao nível de $14 \%$ de caroço de algodão. Apesar das ingestões semelhantes de nitrogênio, a cana-de-açúcar fornecida sem caroço de algodão promove maior excreção urinária de nitrogênio e menor síntese de proteína microbiana em comparação à cana com $14 \%$ de caroço de algodão, o que comprova falta de sincronização na degradação da energia e proteína na relação volumoso:concentrado proposta no estudo.

\section{Literatura Citada}

CHEN, X.B.; GOMES, M.J. Estimation of microbial protein supply to sheep and cattle based on urinary excretion of purine derivatives - an overview of technical details. Aberdeen: Rowett Research Institute, 1992. 21p. (Occasional publication).

CHEN, X.B.; MEJIA, A.T.; DYLE, D.J. et al. Evaluation of the use of purine derivative: creatinine ratio in spot urine and plasma samples as an index of microbial protein supply in ruminants studies in sheep. Journal of Dairy Science, v.125, p.137-143, 1995.

CLARK, J.H.; KLUSMEYER, T.H.; CAMERON, M.R. Microbial protein synthesis and flows of nitrogen fractions to the duodenum of dairy cows. Journal of Dairy Science, v.75, p.2304-2323, 1992.

DEHORITY, B.A. Evaluation of subsampling and fixation procedures used for counting rumen protozoa. Applied and Environmental Microbiology, v.48, p.182-185, 1984.
DelCURTO, T.; COCHRAN, R.C.; CORAH, L.R. et al. Supplementation of dormant allgrass-Prarie forage: II. Performance and forage utilization characteristics in grazing beef cattle receiving supplements of different protein concentrations. Journal of Animal Science, v.68, n.2, p.532-542, 1990.

FARIA, V.P.; HUBER, J.T. Effect of dietary protein and energy levels on rumen fermentation in Holstein steers. Journal of Animal Science, v.58, n.2, p.452 459, 1984.

GONDA, H.L.; LINDBERG, J.E. Effect of diet on milk allantoin and its relationship with urinary allantoin in dairy cows. Journal of Dairy Science, v.80, p.364-373, 1997.

HOOVER, W.H. Chemical factors involved in ruminal fiber digestion. Journal of Dairy Science, v.68, n.1, p.40-44, 1986.

HUNGATE, R.E. The rumen and its microbes. New York: Academic Press Inc., 1966. 67p.

JENKINS, T.C. Lipid metabolism in the rumen. Journal of Dairy Science, v.76, n.12, p.3851 3863, 1993.

KOWALCZYK, J.; ØRSKOV, E.R.; ROBINSON, J.J. et al. Effect of fat supplementation on voluntary food intake and rumen metabolism in sheep. British Journal Nutrition, v.37, n.2, p.251-257, 1977

LENG, R.A.; NOLAN, J.V. Nitrogen-metabolism in the rumen. Journal of Dairy Science, v.67, n.5, p.1072-1089, 1984.

MAGALHÃES, A.L.R.; CAMPOS, J.M.S.; CABRAL, L.S. et al. Canade-açúcar em substituição à silagem de milho em dietas para vacas em lactação: parâmetros digestivos e ruminais. Revista Brasileira de Zootecnia, v.35, n.2, p.591-599, 2006.

MENDONÇA, S.S.; CAMPOS, J.M.S.; VALADARES FILHO, S.C. et al. Balanço de compostos nitrogenados, produção de proteína microbiana e concentração plasmática de ureia em vacas leiteiras alimentadas com dietas à base de cana-de-açúcar. Revista Brasileira de Zootecnia, v.33, n.2, p.493-503, 2004.

MOHAMED, O.E.; SATTER, L.D.; GRUMMER, R.R. et al. Influence of dietary cottonseed and soybean on milk production and composition. Journal of Dairy Science, v.71, n.10, p.2676-2688, 1988.

MORRISON, M.; MACKIE. R.I. Nitrogen metabolism by ruminal microorganisms: current understanding and future perspectives. Australian Journal of Agricultural Research, v.47, n.2, p.227-246, 1996.

NATIONAL RESEARCH COUNCIL - NRC. Nutrient requirements of beef cattle. 7.ed. Washington, D.C.: National Academy Press, 1996. 242p.

NATIONAL RESEARCH COUNCIL - NRC. Nutrient requirements of dairy cattle. 7.ed. Washington, D.C.: National Academy Press, 2001. 381p.

NEVEL, C.J.; DEMEYER, K.I. Manipulation of rumen fermentation. In: HOBSON, P.N. (Ed) The rumen microbial ecosystem. London: Elsevier Applied Science, p.387-443, 1988.

NOLAN, J.V. Nitrogen kinetics. In: FORBES, J.M.; FRANCE, J. (Eds) Quantitative aspects of ruminant digestion and metabolism. Wallinford: CAB International, p.123-143, 1993.

OLIVEIRA, A.S.; VALADARES, R.F.D; VALADARES FILHO, S.C. et al. Produção de proteína microbiana e estimativas das excreções de derivados de purinas e de ureia em vacas lactantes alimentadas com rações isoproteicas contendo diferentes níveis de compostos nitrogenados não-proteicos. Revista Brasileira de Zootecnia, v.30, n.5, p.1621-1629, 2001.

ORELLANA BOERO, P.; BALCELLS, J.; MARTÍN-ORÚE, S.M.; et al. Excretion of purine derivatives in cows: endogenous contribution and recovery of exogenous purine bases. Livestock Production Science, v.68, p.243-250, 2001.

PAULINO, M.F.; DETMANN, E.; ZERVOUDAKIS, J.T. Suplementos múltiplos para recria e engorda de bovinos em pastejo. In: SIMCORTE, 2., 2001, Viçosa, MG. Anais... Viçosa, MG: Universidade Federal de Viçosa, 2001. p.187-232. 
POPPI, D.P.; McLENNAN, S.R. Protein and Energy utilization by ruminants at pasture. Journal of Animal Science, v.73, p.278-290, 1995.

RABELO, T.G. Grão de soja moído na alimentação de vacas lactantes. 1995. 114f. Dissertação (Mestrado em Zootecnia) - Universidade Federal de Viçosa, Viçosa, MG, 1995.

RAUN, N.S.; BURRONGHS, W.; WORDS, W. Dietary factors affecting volatile fatty acids production in the rumen. Journal of Animal Science, v.21, p.838-844, 1962.

RENNÓ, L.N.; VALADARES, R.F.D.; VALADARES FILHO, S.C. et al. Concentração plasmática de ureia e excreções de ureia e creatinina em novilhos. Revista Brasileira de Zootecnia, v.29, n.4, p.1235-1243, 2000.

SATTER, L.D.; SLYTER, L.L. Effect of ammonia concentration on rumen microbial production in vitro. British Journal of Nutrition, v.32, p.199-208, 1974.

SCHABENBERGER, O.; PIERCE, F.J. Contemporary statistical models for the plant and soil sciences. New York: CRC Press, 2002. 738p.

SILVA, D.J.; QUEIRÓZ, A.C. Análise de alimentos (métodos químicos e biológicos). 2.ed. Viçosa, mg: Universidade Federal de Viçosa, Imprensa Universitária, 2002. 235p.

SNIFFEN, C.J.; O'CONNOR, J.D.; VAN SOEST, P.J. et al. A net carbohydrate and protein system for evaluating cattle diets; II. Carbohydrate and protein availability. Journal of Animal Science, v.70, n.11, p.3562-3577, 1992.

SOUSA, D.P.; CAMPOS, J.M.S.; VALADARES FILHO, S.C. et al. Comportamento ingestivo, consumo e digestibilidade de nutrientes, produção e composição do leite de vacas alimentadas com silagem de milho ou cana-de-açúcar com caroço de algodão. Revista Brasileira de Zootecnia, v.38, n.10, p.2053-2062, 2009.

SOUZA, A.L.; GARCIA, R.; VALADARES, R.F.D. et al. Casca de café em dietas para vacas em lactação: balanço de compostos nitrogenados e síntese de proteína microbiana. Revista Brasileira de Zootecnia, v.35, n.4, p.1860-1865, 2006.
STATISTICAL ANALYSIS SYSTEM - SAS. SAS Systems for linear models. Cary: SAS Institute, 1991. 329p.

VAGNONI, D.B.; BRODERICK, M.K.; CLAYTON, R.D. et al. Excretion of purine deriva4ives by Holstein cows abomasally infused with incremental amounts of purines. Journal of Dairy Science, v.80, p.1695-1702, 1997.

VALADARES, R.F.D.; BRODERICK, G.A.; VALADARES FILHO, S.C. et al. Effect of replacing alfalfa silage with high moisture corn on ruminal protein synthesis estimated from excretion of total purine derivatives. Journal of Dairy Science, v.82, n.12, p.2686-2696, 1999.

VALADARES, R.F.D.; GONÇALVES, L.C.; SAMPAIO, I.B. et al. Níveis de proteína em dietas de bovinos 4. Concentrações de ureia plasmática e excreções de ureia e creatinina. Revista Brasileira de Zootecnia, v.26, n.6, p.1270-1278, 1997.

VALVASORI, E.; LAVEZZO, W.; LUCCI, C.A. et al. Alterações na fermentação ruminal de bovinos fistulados alimentados com cana-de-açúcar em substituição á silagem de milho. In: REUNIÃO ANUAL DA SOCIEDADE BRASILEIRA DE ZOOTECNIA, 35. 1998, Botucatu. Anais... Botucatu: Sociedade Brasileira de Zootecnia, p.86-88, 1998.

VAN der WALT, J.G. Nitrogen metabolism of the ruminant liver. Australian Journal of Agricultural Research, v.44, n.3, p.381-403, 1993.

VAN SOEST, P.J. Nutritional ecology of the ruminant. 2.ed. Ithaca: Cornell University Press, 1994. 476p.

VAN SOEST, P.J.; ROBERTSON, J.D.; LEWIS, B.A. Methods for dietary fiber, neutral detergent fiber, nonstarch polysaccharides in relation to animal nutrition. Journal Dairy Science, v.74, p.3583-3597, 1991.

VERBIC, J.; CHEN, X.B.; MACLEOD, N.A. et al. Excretion of purine derivatives by ruminants. Effect of microbial nucleic acid infusion on purine derivative excretion by steers. Journal of Agricultural Science, v.114, n.3, p.243-248, 1990. 